\title{
Modelling Nonlinear Relationship among Selected ASEAN Stock Markets
}

\author{
Mohd Tahir Ismail ${ }^{1}$ and Zaidi Bin $\mathrm{Isa}^{2}$ \\ ${ }^{1}$ Universiti Sains Malaysia and ${ }^{2}$ Universiti Kebangsaan Malaysia
}

\begin{abstract}
The Asian financial crisis that struck most of the East Asian countries in 1997 have caught the attention of many researchers in finance and economic. This is due to realization that during the crisis the countries affected saw their currencies depreciate for more than $50 \%$ and their stock markets sharply fall about $30 \%$ to $50 \%$. In this paper, we investigate the relationship among the return of stock markets from three Southeast Asian countries (Malaysia, Singapore and Thailand) or the ASEAN countries using monthly data between 1990 and 2004. We found the three stock markets are not cointegrated. Therefore, instead of modelling the returns data using linear vector autoregressive (VAR) models, we assume the returns data are regime-dependent and we use the two regime multivariate Markov switching vector autoregressive (MS-VAR) model with regime shifts in both the mean and the variance to extract common regime shifts behaviour from the return series. It is found that MS-VAR model with two regimes manage to detect common shifts in all the stock markets return series and this show evidence of comovement among the three returns series. Furthermore, we also found that the MS-VAR model manage to capture a satisfactory timing of the 1997 financial crisis that happen in the three countries.
\end{abstract}

Key words: Markov switching vector autoregression model, nonlinearity, stock price.

\section{Introduction}

Since the 1987 stock market crash, many stock markets around the world had been in the bulling periods for a along time. However this situation had changed in the middle of 1997 for many of the East Asian countries. This is because financial crisis had struck many of these countries because of speculative attacks on their currencies. The crisis is in fact begun to affect Thailand before spreading to Malaysia, the Philippine, Singapore, Indonesia and eventually to South Korea. During the crisis all the countries affected saw turmoil in both their currencies and stock markets. As a result, this crisis has captured the attention of many 
researches. The researchers focus their studies on the relationship among the exchange rates (Reside and Gochoco-Bautista (1999), Fujii (2002), Au Yong, Gan and Treepongkaruna (2004)), among the stock markets (Chartarjee, Ayadi and Maniam (2003), Daly (2003), Yang, Kalori and Min (2003)) and the interaction between the exchange rate and the stock market (Wu (2000), Phylaktis and Ravazzola (2005), Doong, Yang and Wang (2005)) during and after the 1997 financial crisis.

All literatures mentioned above use similar methodology to analyse the relationship among or between the stock price and exchange rate. They begin their studies by finding whether the variables are cointegrated or not using cointegration test and later modelling the variables using vector autoregressive (VAR) model or vector error correction (VEC) model to show the existent of short run relationship or long run relationship among the variables. However in this paper we use different methodology to study the interaction among selected ASEAN countries stock markets. The focus of our study is to investigate whether nonlinear relationship because of common regime switching behaviour exists in the selected stock markets. Thus, we assume all the series are regime dependent. Therefore, a two regime multivariate Markov switching vector autoregressive (MS-VAR) model with regime shifts happen in both the mean and the variance is going to be used to extract common regime switching behaviour from all the series.

Moreover, previous studied by Chartarjee, Ayadi and Maniam (2003), Daly (2003) and Yang, Kalori and Min (2003) divided the data into two sub periods of pre and post 1997 financial crisis to study the impact before and after the crisis on the Southeast Asian stock markets. In contrast, the MS-VAR model captures the sudden changes in the data using an exogenous variable which is unobserved and follow a stochastic process; Markov process. Therefore, the sudden changes are representing by a probabilistic statements which are called the transition probabilities. The advantage of using the transition probabilities is that it specifies which regime occurs at each point in the time rather than imposing particular dates at priori. Thus it allows the data to tell the nature and incidence of significant shifts. In addition, the MS-VAR model has gains much attention because of its flexibility. This is because the MS-VAR model can capture regime shifts in the mean, in the variance and also the parameter of the vector autoregressive process.

The reminder of this paper is organized as follow. Section 2 introduces the multivariate Markov switching model specification. Section 3 presents the empirical results and discussion on the results. Section 4 contains the summary and the conclusion. 


\section{The Markov Switching Vector Autoregressive Model}

The univariate Markov switching autoregressive model (MS-AR) was originally developed by Hamilton (1989) to define changes between fast and slow growth regimes in the US economy. Hamilton $(1993,1994)$ assumed that in the MS-AR model, the time series, $y_{t}$ is normally distributed with $\mu_{i}$ in each of $k$ possible regime where $i=1, \ldots, k$. A MS-AR model of two states with an AR process of order $p$ with label by $\operatorname{MS}-\operatorname{AR}(p)$ is given as follow:

$$
\begin{aligned}
y_{t} & =\mu\left(s_{t}\right)+\left[\sum_{i=1}^{p} \alpha_{i}\left(y_{t-i}-\mu\left(s_{t-i}\right)\right)\right]+u_{t} \\
u_{t} \mid s_{t} & \sim N I D\left(0, \sigma^{2}\left(s_{t}\right)\right) \text { and } s_{t}=1,2,
\end{aligned}
$$

where $\alpha_{i}$ are the autoregressive parameters with $i=1, \ldots, p$.

The MS-AR model framework of Equation (2.1) can be readily extended to the multivariate MS-VAR model of order $p$ with two regimes that allow the mean and the variance to shifts simultaneously across the regimes and is given below;

$$
Y_{t}-\psi\left(s_{t}\right)=A_{1}\left(s_{t}\right)\left(Y_{t-1}-\psi\left(s_{t-1}\right)\right)+\cdots+A_{p}\left(Y_{t-p-\psi\left(s_{t-p}\right)}\right)+\epsilon_{t},
$$

where $Y_{t}=\left(Y_{1 t}, \ldots, Y_{n t}\right)^{\prime}$ is an $n$ dimensional time series vector, $\psi$ is the vector of means, $A_{1}, \ldots, A_{p}$ are the matrices containing the autoregressive parameters and $\epsilon_{t}$ is a white noise vector process such that $\epsilon_{t} \mid s_{t} \sim N I D\left(0, \Sigma\left(s_{t}\right)\right)$. Furthermore, other specifications of MS-VAR model are discussed in monograph by Krolzig (1997).

From Equation (2.1) and (2.2), $s_{t}$ is a random variable that triggers the behaviour of $Y_{t}$ to change from one regime to another. Therefore the simplest time series model that can describe a discrete value random variable such as the unobserved regime variable $s_{t}$ is the Markov chain. Generally, $s_{t}$ follow a first order Markov process where it implies that the current regime $s_{t}$ depends on the regime one period ago, $s_{t-1}$ and denoted as;

$$
\operatorname{Pr}\left(s_{t} \mid s_{t-1}=i, s_{t-2}=k, \cdots\right)=\operatorname{Pr}\left(s_{t} \mid s_{t-1}=i\right)=p_{i j},
$$

where $p_{i j}$ is the transition probability from one regime to another. For $m$ regimes, these transition probabilities can be collected in a $(m \times m)$ transition matrix denoted as $P$ :

$$
P=\left[\begin{array}{cccc}
p_{11} & p_{12} & \cdots & p_{1 m} \\
p_{21} & p_{22} & \cdots & p_{2 m} \\
\vdots & & & \\
p_{m 1} & p_{m 2} & \cdots & p_{m m}
\end{array}\right]
$$


with $\sum_{j=1}^{m} p_{i j}=1, i=1,2, \ldots, m$ aand $0 \leq p_{i j} \leq 1$.

The transition probabilities also provide us with expected duration that is the expected length the system is going to be stay in a certain regime. Let $D_{j}$ define the duration of regime $j$. Then, the expected duration of the regime $j$ is given by

$$
E\left(D_{j}\right)=\frac{1}{1-p_{j j}}, \quad j=1,2, \ldots
$$

An algorithm suggested by Hamilton's (1989) to estimate the MS-AR model consists of two parts. In the first part, population parameters including the joint probability density of unobserved regimes $s_{t}$ are estimated and in the second part, probabilistic inferences about the unobserved regimes are made by using a nonlinear filter and smoother. Filter probabilities $P\left(s_{t}=j \mid \Omega_{t}\right)$ are inferences about $s_{t}$ conditional on information up to time $t, \Omega$ and smoothed probabilities $P\left(s_{t}=j \mid \Omega_{T}\right)$ are inferences about $s_{t}$ by using all the information available in the sample, $\Omega_{T}$ where $t=1,2, \ldots, T$.

The conventional procedure for estimating the model parameters is to maximize the log-likelihood function and then use these parameters to obtain the filtered and smoothed inferences for the unobserved regime variable $s_{t}$. However this method becomes disadvantageous as the number of parameters to be estimated increases. Generally in such cases, the Expectation Maximization (EM) algorithm is used. This technique starts with the initial estimates of the unobserved regime variable, $s_{t}$ and iteratively produces a new joint distribution that increases the probability of observed data. These two steps are referred to as expectation and maximization steps. The EM algorithm has many desirable properties as stated in Hamilton (1990, 1993, and 1994) and Kim and Nelson (1999).

\section{Application to Selected ASEAN Stock Markets}

In this section we will present the results of the econometric specifications used for modelling the common trend of stock market index from three ASEAN countries. This section begins by giving a description of the data and testing for stationary using a unit root test and a stationary test. Then if the data is stationary at the same order, we use Johansen test to examine the existent of cointegration. Later, we test the return series of the stock market index for nonlinearity. Finally, we estimate the MS-VAR model and collected a series of smoothing probabilities to identify common regime switching behaviour in the three series. 


\subsection{Data}

The data under investigation are the monthly stock market indices of three ASEAN countries over the period from January 1990 to May 2004 for a total of 173 observations. The three stock market indices considered are the KLCI Index (Malaysia), the STI Index (Singapore) and the SETI Index (Thailand). The series are collected from Far Eastern Economic Review for the KLCI Index and the SETI Index and from www.econstat.com for the STI Index. The three series are analysed in returns, which is the first difference of natural logarithms multiplied by 100 to express things in percentage terms. Figure 1 shows the behaviour of the return series of the KLCI Index, the STI Index and the SETI Index over the study period. It is clear from Figure 1 that until the middle of 1997 volatility is less pronounced, while thereafter it rises substantially. This is because the three countries were affected by the 1997 Asian financial crisis.
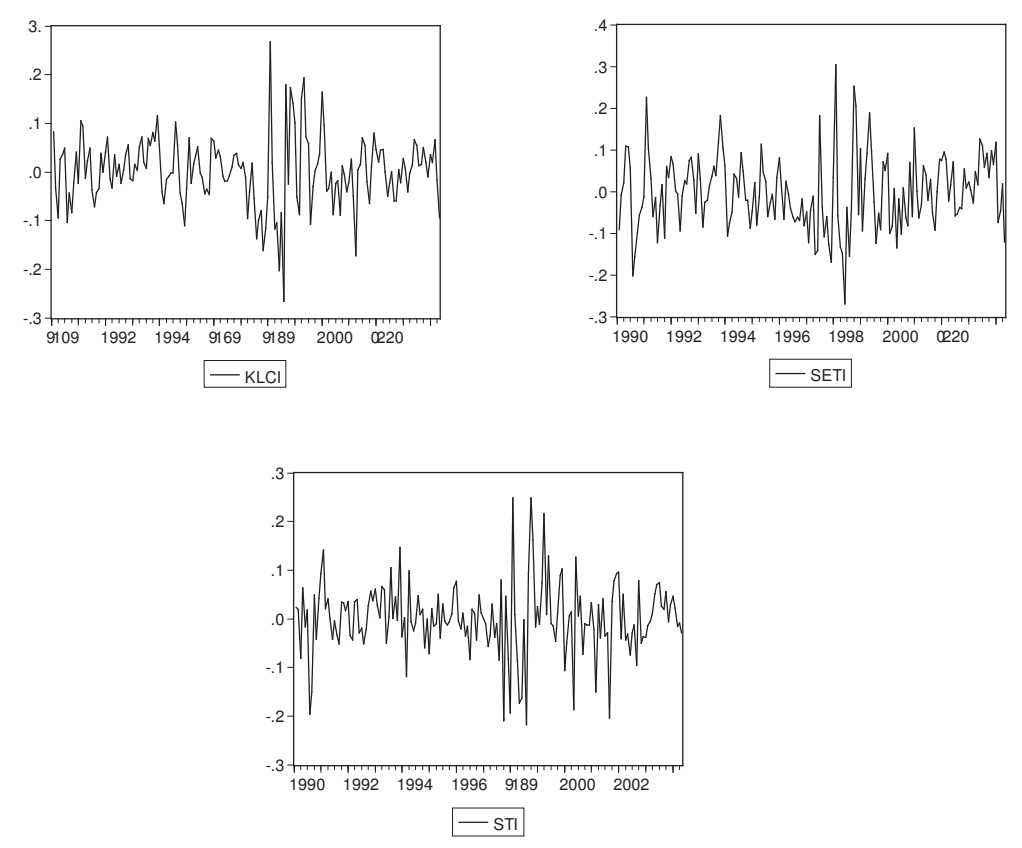

Figure 1: Monthly return series

\subsection{Stationarity and cointegration tests}

Based on suggestion by Brooks (2002, pp 382) a confirmatory data approach is going to be used to test whether the three return series are stationary in the 
level or in first differences. The confirmatory data analysis consist of jointly use of stationarity and unit root tests to investigate the stationary of a series. The unit root test, test the null hypothesis that a series contains a unit root against an alternative hypothesis that a series is stationary, whereas it is reversible for stationarity test. In this paper, we employ the ADF test (unit root test) by Dickey and Fuller $(1979,1981)$ and the KPSS test (stationarity test) by Kwiatkowski, Phillips, Schmidt and Shin (1992) to test the stationary of KLCI, SETI and STI series. All the series are being analysed in levels and in first-differences. From Table 1 at $5 \%$ critical value all the series are stationary at first-difference, indicating all are $I(1)$ processes.

Table 1: Tests for Stationary in the Series

\begin{tabular}{lcccc}
\hline Index & $\begin{array}{c}\text { Level/ } \\
\text { first difference }\end{array}$ & ADF test & KPSS test & Conclusion \\
& Level & -2.41 & $0.199^{*}$ & \\
\hline \multirow{2}{*}{ KLCI } & First difference & $-8.25^{*}$ & 0.070 & $\mathrm{I}(1)$ \\
\hline \multirow{2}{*}{ SETI } & Level & -2.11 & $0.186^{*}$ & $\mathrm{I}(1)$ \\
& First difference & $-8.61^{*}$ & 0.048 & \\
\hline \multirow{2}{*}{ STI } & Level & -2.19 & $0.178^{*}$ & $\mathrm{I}(1)$ \\
& First difference & $-13.35^{*}$ & 0.063 & \\
\hline
\end{tabular}

Having established the order of integration, we proceed to the next step by testing cointegrating relationships among the series using Johansen multivariate cointegration test. This test was first introduced by Johansen (1988) and was discussed extensively in Johansen and Juselius (1990). As shown in Table 2, we cannot reject the null hypothesis of no cointegration among the stock index return series. This implies that there is no long run relationship among all the series. Therefore the error correction term is not taken into account in later empirical models and analyses.

Table 2: Cointegration Tests among the Series

\begin{tabular}{lccccc}
\hline $\begin{array}{l}\text { The number of } \\
\text { Relationship vector }\end{array}$ & \multicolumn{2}{c}{$\begin{array}{c}\text { Maximum eigenvalues } \\
\text { statistics }\end{array}$} & & \multicolumn{2}{c}{ Trace statistics } \\
\cline { 2 - 3 } \cline { 5 - 6 } & $\hat{\lambda}_{\text {max }}$ & $5 \%$ critical value & & $\hat{\lambda}_{\text {trace }}$ & $5 \%$ critical value \\
\hline$r=0$ & 13.19 & 20.97 & & 23.15 & 29.68 \\
$r=1$ & 7.651 & 14.07 & & 9.960 & 15.41 \\
$r=2$ & 2.309 & 3.76 & & 2.309 & 3.76 \\
\hline
\end{tabular}




\subsection{Nonlinearity testing}

To justify the used of nonlinear MS-VAR model, we use three portmanteau tests to test departures from linearity in the returns series. The three tests are the McLeod-Li test, the RESET test and the BDS test. The McLeod-Li test was proposed by McLeod and Li (1983) and the objective of this test is to determine whether there is a significant autocorrelation in the squared residuals from a linear equation. The Regression Error Specification Test or RESET test suggest by Ramsey (1969) is a specification test for linear least squares regression analysis. The BDS test is derived and discussed by Brock et al. (1996) to test the null hypothesis of independently and identically distributed (iid) in the data. In a small sample or series with unusual distribution, the distribution of the BDS statistic departs from asymptotic normal distribution. As a result, a bootstrapped $p$-value is calculated.

From Table 3, the BDS test, the McLeod-Li test and the RESET test suggested that linear model may be inadequate in capturing the stochastic properties of the return series. This is because one or all the three portmanteau tests showed significant results (the p-values are small) for each of the returns series. This result justified the use of nonlinear model in modelling the returns of KLCI Index, SETI Index and STI Index. Besides, it suggests that in testing for nonlinearity it is unwise to rely solely on a single test.

Table 3: Testing for nonlinearity

\begin{tabular}{lccc}
\hline Test/Index & BDS & RESET & McLeod-Li $(20)$ \\
\hline \multirow{2}{*}{ KLCI } & 5.68 & 4.21 & 115.9 \\
& $(.000)$ & $(.007)$ & $(.000)$ \\
SETI & 2.68 & 0.93 & 71.61 \\
& $(.007)$ & $(0.42)$ & $(.000)$ \\
STI & 3.13 & 0.44 & 76.32 \\
& $(.002)$ & $(0.64)$ & $(.000)$ \\
\hline
\end{tabular}

The numbers of the squared residuals have to be determined before the McLeod and Li test can be conducted. Usually 20 of the squared residuals are used in the test.

\subsection{Model estimation results}

Using the Principle of Parsimony we found that two regimes Markov switching vector autoregressive model of order one with switching in the mean and the variance or MS-VAR(1) manage to capture the interaction among the three series very well. All the results are presented in Table 5. Before we further discuss the 
Table 4: Model comparison

\begin{tabular}{lcc}
\hline & $M S-V A R(1)$ & Lineaar $V A R(1)$ \\
\hline Log-likelihood & -1623.6514 & -1680.8995 \\
AIC & 19.3293 & 19.8702 \\
HQC & 19.5454 & 20.0044 \\
SBC & 19.8621 & 20.2009 \\
LR test & 114.4961 & \\
& {$[.000]$} & \\
\hline
\end{tabular}
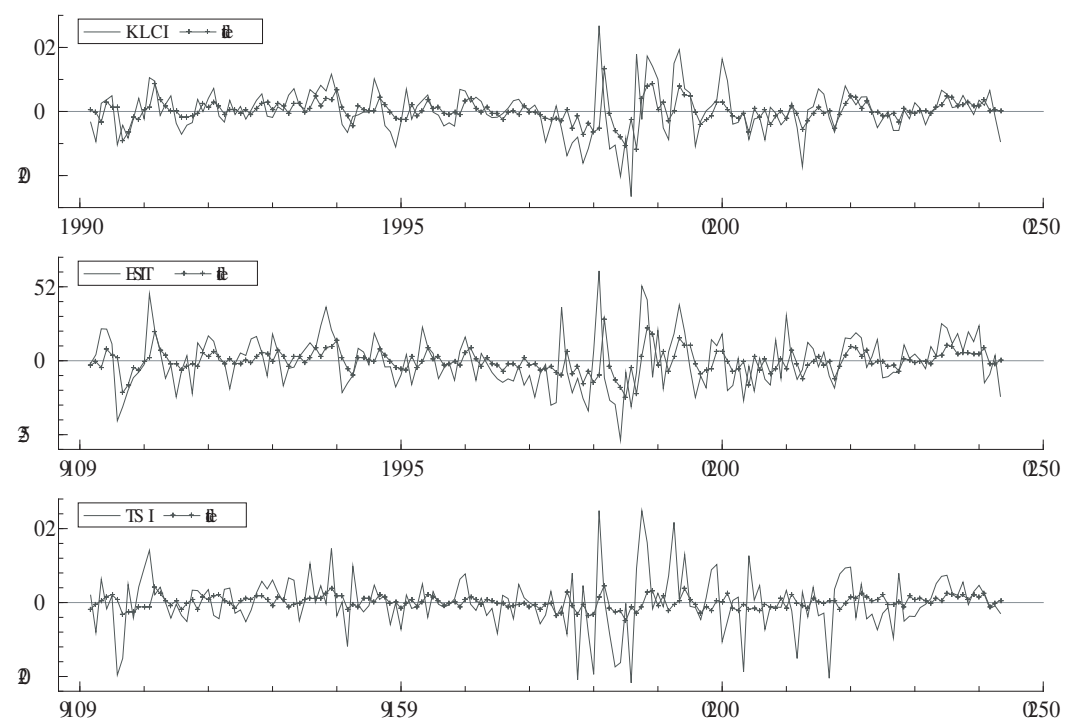

Figure 2: Fit of the $M S-V A R(1)$ model, 1990-2004

estimation model, using the likelihood ratio test or LR test suggested by Garcia and Perron (1996), we are going to determine whether regime shifts happen in three stock market returns.

In the last section, statistically we manage to capture the existent of nonlinear behaviour in all the series. Therefore, based on likelihood ratio test (LR test) suggested by Garcia and Perron (1996), we show that nonlinear behaviour that existed in all the return series are regime switching behaviour. The LR test statistic is computed as $L R=2\left|\ln L_{M S-V A R}-\ln L_{V A R}\right|$ where $\ln L$ is the $\log$ likelihood and the critical value is based on Davies (1987) $p$-value. The results from Table 4 imply very strong rejection of the null hypothesis of no switching at $1 \%$ or $5 \%$ critical values. This is because the Davies (1987) $p$-value (value in the [ ] bracket) shows a very significant result. Therefore, it is clear that there is a strong evidence of regime switching behaviour in all the return series. 
From Table 4, we also calculate the model selection criteria and found that the AIC (Akaike), HQC (Hannan-Quinn) and SBC (Schwartz Bayesian) criteria produced a minimum values for the MS-VAR(1) model. This results show that the performance of the MS-VAR(1) models are better than the nested linear VAR(1) model. Additional evidence in favour of the MS-VAR(1) is provided by plots of the actual and fitted values for each return series given in Figure 2 where the fit of the model seem to be good. From all the results, we can conclude that nonlinear model is better describing the data than linear model.

Moreover, it can be seen from Table 5 that the estimated parameters of the MS-VAR(1) model for each of the two regimes has a clear economic interpretation. The first regime $\left(s_{t}=1\right)$ indicates that all the stock market indices are in the Bull market or expansion phase with positive sign of the monthly expected return, $\mu\left(s_{t}=1\right)$ and lower volatility, $\sigma^{2}\left(s_{t}=1\right)$. Conversely the second regime captures the Bear market or contraction phase of the stock market indices with negative sign of the monthly expected return, and higher volatility $\sigma^{2}\left(s_{t}=2\right)$. In addition, the probability of staying in regime $1, P\left(s_{t}=1 \mid s_{t-1}=1\right)=0.9820$ is higher than the probability of staying in regime $2, P\left(s_{t}=2 \mid s_{t-1}=2\right)=0.9603$ with suggest that regime $1\left(s_{t}=1\right)$ is more persistent than regime $2\left(s_{t}=2\right)$. Thus, an average all the series staying longer in regime 1 which is about 56 months compare to staying in regime 2 which is only 25 months. This results unveil that only an extremely event can switch the series to change from regime 1 to regime 2 .

Table 5: ML estimation results for the $M S-V A R(1)$ model

\begin{tabular}{lrrr}
\hline & $K L C I_{t}$ & $S E T I_{t}$ & $S T O I_{t}$ \\
\hline$\mu\left(s_{t}=1\right)$ & 0.707140 & 0.378550 & 0.452411 \\
$\mu\left(s_{t}=2\right)$ & $(1.1307)$ & $(0.4062)$ & $(0.8680)$ \\
& -0.852910 & -1.082557 & -0.503183 \\
$K L C I_{t-1}$ & $(-0.4575)$ & $(-0.4556)$ & $(-0.3201)$ \\
& $0.155813^{* *}$ & 0.058568 & 0.029389 \\
$S E R I_{t-1}$ & $(1.7814)$ & $(0.4897)$ & $(0.2945)$ \\
$S T)_{t-1}$ & $0.124615^{* *}$ & $0.240639^{* *}$ & $0.187680^{* *}$ \\
$\sigma^{1}\left(s_{t}=1\right)$ & $(1.9785)$ & $(2.7481)$ & $(2.6550)$ \\
$\sigma^{1}\left(s_{t}=2\right)$ & $0.233030^{* *}$ & $0.238381^{* *}$ & -0.061170 \\
$p_{i j}$ & $(3.1553)$ & $(2.3932)$ & $(-0.7278)$ \\
$s_{t}=1$ & 3.790863 & 5.850211 & 4.482673 \\
$s_{t}=2$ & 9.145784 & 11.020925 & 10.496888 \\
& $s_{t-1}=1$ & $s_{t-2}=2$ & $E\left(D_{s_{t}}\right)$ \\
& 0.9820 & 0.0180 & 55.64 \\
& 0.0397 & 0.9603 & 25.20 \\
\hline
\end{tabular}

Please refer to Equation (2.2) for full specification of the equation Figures in the parenthesis are the t-values, ${ }^{* *}$ significance at the $5 \%$ level 
To further justified our interpretation about regime 1 and regime 2 using the estimated parameters of the MS-VAR(1) model, Figure 3 shows the smoothed regime probability plots which is the probability of staying in either regime 1 or regime 2 at time $t$. As shown on Figure 3, the smoothed probability plots of regime 2 manage to identify crises periods around the world that affected the three ASEAN stock market indices. It seems that the probabilities of regime 2 are near one around 1990 and around 1997. These two periods are inline with the Gulf War from 1990 to 1991 and the financial crisis that struck many of East Asian countries. On the contrary the smoothed probabilities of regime 1 are near one just after the smoothed probabilities of regime 2 are near zero or just after the crises periods. This means regime 1 is the recovery and expansion period for the three stock market indices.

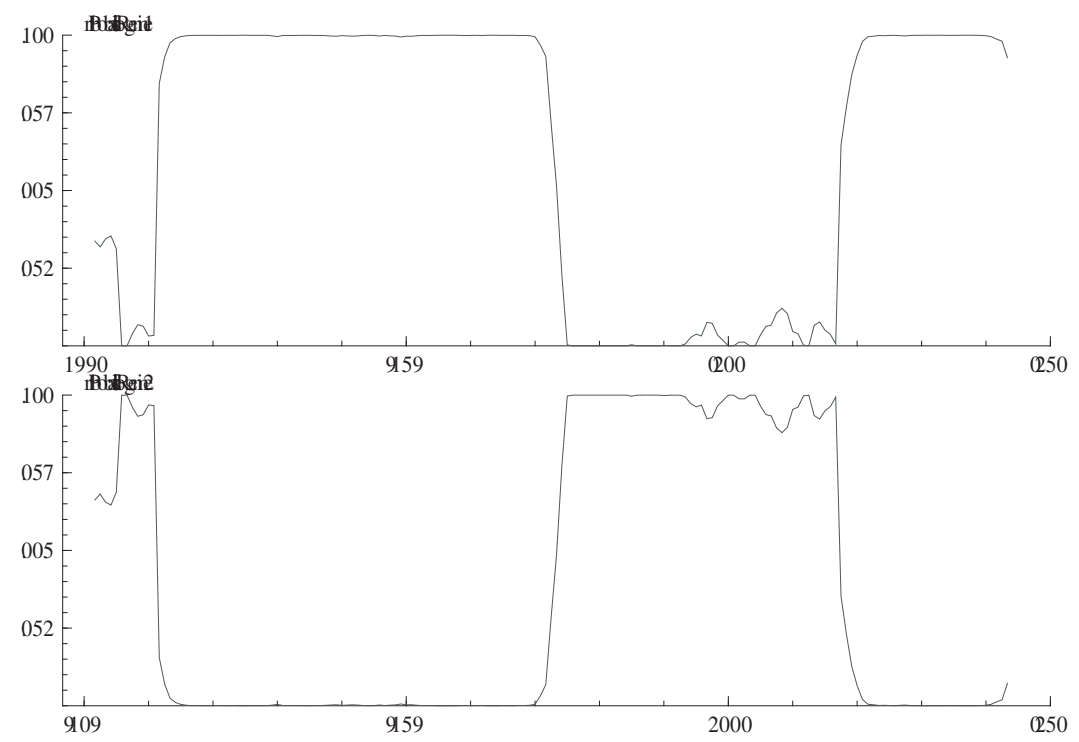

Figure 3: Smoothed probability plots of the $M S-V A R(1)$ model

Additional investigation on smoothed probability plots of regime 2 (refer to Figure 3) reveals that the first crisis captured by the MS-VAR(1) model that affected the three stock market returns begin on March 1990 and end around February 1991. This crisis occurred because of crude oil price increases due to less production. This situation arises because of the Gulf War. Raymond and Rich (1997) manage to capture this 1990-91 oil price crisis using the bivariate Markov switching model when they studied the relationship between the oil price changes and the US GDP. Whereas, the MS-VAR(1) model uncover that the second crisis period start on Jun 1997 and last until September 2001. Based on 
article by Burton and Thornhill (2001), although many of East Asian countries recover from the 1997 financial crisis around the year 2000, because of recession period in the US due to the fall of US IT industry all the countries return to recession period again. As a result, the second crisis affected the three stock markets for 25 months before all the stock markets return to expansion period.

\section{Conclusion}

This paper investigates the nonlinear relationship among stock market indices from three ASEAN countries from 1990 until 2005. The result indicates that the three indices are not cointegrated. Moreover, the three portmanteau tests suggest that a nonlinear model is more appropriate compared to linear model but did not give information regarding the nature of the nonlinearity. Therefore, instead of modelling the returns series as a linear VAR model we employed a two regimes multivariate Markov switching vector autoregressive (MS-VAR) model with regime shifts in both the mean and the variance to extract common regime switching behaviour. Ours finding can be summarized as follow. Firstly, using the LR test, we can reject linearity in the return series with imply that there is regime switching structure in all the series. Secondly we found that the three return series are well fitted by the MS-VAR(1) model and a common regime switching behaviour can be extracted. This is shown by the estimated parameters and the smoothed probability plots of regime 1 and regime 2 . In addition we also found that the MS-VAR(1) model manages to capture a satisfactory timing of the two crisis period that affected the three stock markets. Finally we concluded that there is evidence of comovement among the three stock market indices because we manage to extract common regime switching behaviour among them.

\section{References}

AuYong, H. H., Gan, C. and Treepongkaruna, S. (2004). Cointegration and causality in the Asian and emerging foreign exchange markets: Evidence from the 1990s financial crises. International Review of Financial Analysis 13, 479-515.

Brock, W. A., Dechert, W. D., Scheinkman, J. and LeBaron, B. (1996). A test for independence based on the correlation dimension. Econometrics Reviews 155, $197-235$.

Brooks, C. (2002). Introductory Econometrics for Finance. Cambridge University Press.

Burton, J. and Thornhill, J. (2001). Asia falling: a sudden reversal of their recovery from the economic crash of 1997-98 is forcing the region's government to confront basic structural weakness. Financial Time- UK Edition, August: 16. 
Chatterjee, A., Ayadi, O. F. and Maniam, B. (2003). Asian financial crises: the preand post- crisis analysis of Asian equity markets. Managerial Finance 29, 62-86.

Daly, K. J. (2003). Southeast Asian stock market linkages: evidence from pre- and post-October 1997. ASEAN Economic Bulletin 20, 73-85.

Davies, R. B. (1987). Hypothesis testing when a nuisance parameter is present only under the alternative. Biometrika 74, 33-43.

Dickey, D. A. and Fuller, W. A. (1979). Distribution of the estimators for autoregressive time series with a unit root. Journal of the American Statistical Association 74, 427-431.

Dickey, D. A. and Fuller, W. A. (1981). The likelihood ratio statistics for autoregressive time series with a unit root. Econometrica 49, 1057-1072.

Doong, S. C., Yang, S. Y. and Wang, A. T. (2005). The dynamic relationship and pricing of stocks and exchange rates: empirical evidence from Asian emerging markets. Journal of American Academy of Business 7, 118-123.

Fujii, E. (2002). Exchange rate and price adjustments in the aftermath of the Asian crisis. International Journal of Finance and Economics 7, 1-14.

Garcia, R. and Perron, P. (1996). An analysis of the real interest rate under regime shifts. Review of Economics and Statistics 78, 111-125.

Hamilton, J. D. (1989). A new approach to the economic analysis of nonstationary time series and the business cycle. Econometrica 57, 357-384.

Hamilton, J. D. (1990). Analysis of time series subject to changes in regime. Journal of Econometrics 57, 39-70.

Hamilton, J. D. (1993). Estimation, inference and forecasting of the time series subject to changes in regime. In Handbook of Statistics v. 11 (Edited by Maddala, G. S., Rao, C. R. and Vinod, H. D.), 231-260. North-Holland.

Hamilton, J. D. (1994). Time Series Analysis. Princeton University Press.

Johansen, S. (1988). Statistical analysis of cointegration vectors. Journal of Economic Dynamics and Control 12, 213-254.

Johansen, S. and Juselius, K. (1990). Maximum likelihood estimation and inference on cointegration with applications to the demand for money. Oxford Bulletin of Economics and Statistics 52, 169-210.

Kim, C. J. and Nelson, C. R. (1999). State-space Models with Regime Switching: Classical and Gibbs-sampling Approaches with Application. The MIT Press.

Krolzig, H. -M. (1997). Markov-switching Vector Autoregression. Springer.

Kwiatkowski, D., Phillips, P. C. B., Schmidt, P. and Shin, Y. (1992). Testing the null hypothesis of stationarity against the alternative of a unit root. Journal of Econometrics 54, 159-178. 
McLeod, A. I. and Li, W. K. (1983). Diagnostic checking ARMA time series models using squared residual correlations. Journal of Time Series Analysis 4, 269-273.

Phylaktis, K. and Ravazzola, F. (2005). Stock prices and exchange rate dynamics. Journal of International Money and Finance 24, 1031-1035.

Raymond, J. E. and Rich, R. W. (1997). Oil and the macroeconomy: a Markov stateswitching Approach. Journal of Money, Credit and Banking 29, 193-213.

Reside, R. E. and Gochoco-Bautista, M. S. (1999). Contagion and the Asian currency crisis. The Manchester School 67, 460-474.

Wu, Y. (2000). Stock prices and exchange rates in a VEC model - The case of Singapore in the 1990s. Journal of Economics and Finance 24, 260-274.

Yang, J., Kalori, J. W. and Min, I. (2003). Stock market integration an financial crises: the case of Asia. Applied Financial Economics 13, 477-486.

Received March 8, 2007; accepted April 4, 2007.

Mohd Tahir Ismail

School of Mathematical Sciences

Universiti Sains Malaysia

11800 Minden, Penang, Malaysia

mtahir@cs.usm.my

Zaidi Bin Isa

School of Mathematical Sciences

Universiti Kebangsaan Malaysia

Bangi, 43600, Selangor, Malaysia

zaidiisa@pkrisc.cc.ukm.com 